\title{
Ergodesign e arquitetura da informação: trabalhando com o usuário
}

Ergodesign and information architecture: working with user

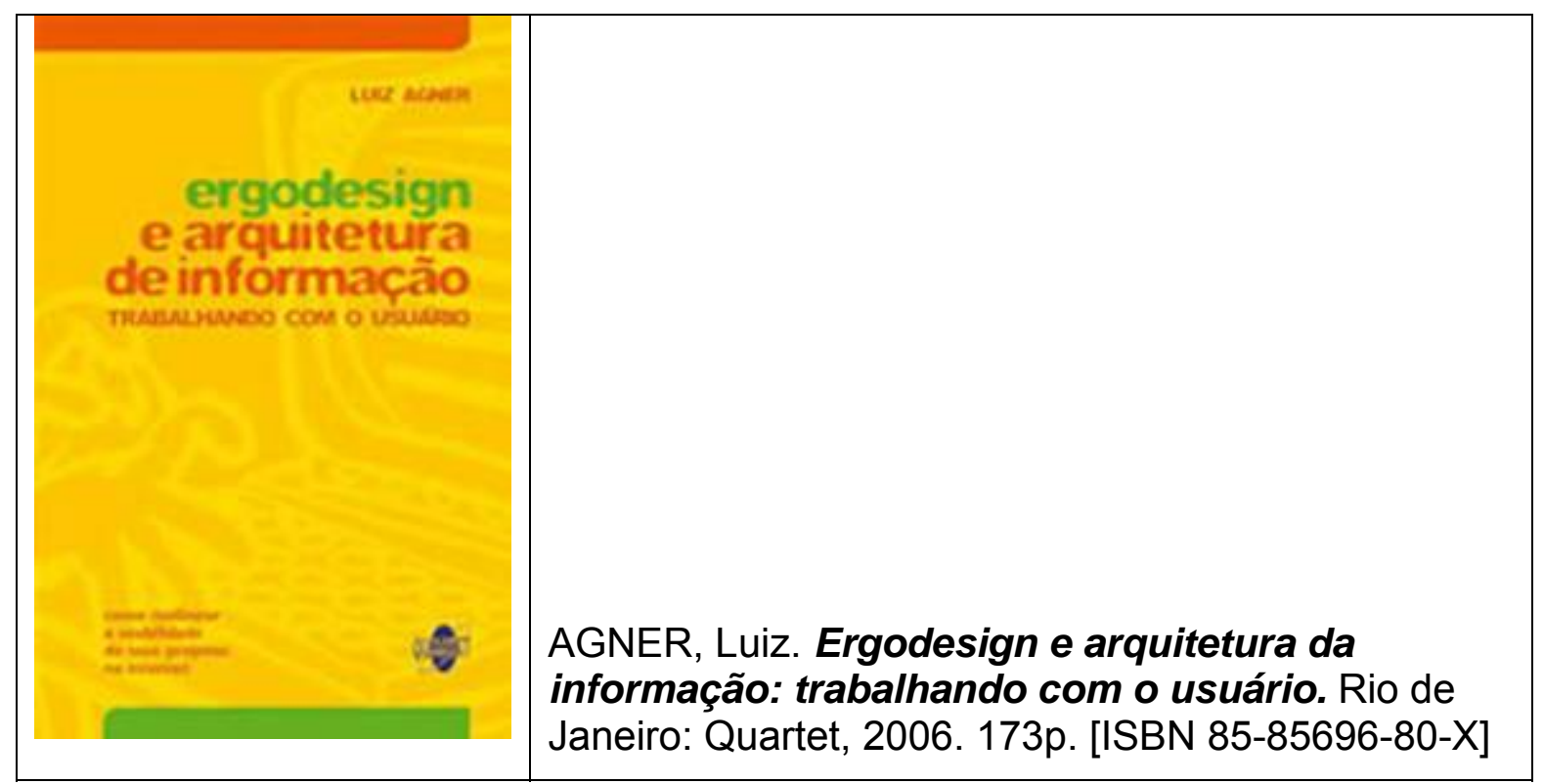

Resumo da obra

Ergodesign e arquitetura da informação faz uma abordagem de questões de design centrado no usuário sob diferentes pontos de vista: clientes, designers, analistas de sistemas e arquitetos da informação. Voltado para o público ainda leigo (interessados em ingressar no campo), se desenvolve a partir de e sobre este foco, de maneira simples, num linguajar coloquial. "Se como diz o autor, Luiz Agner, a crise atual é mesmo de "como transformar informação em conhecimento", ele começou a dar combate à crise ao optar por produzir um livro de forma bem-humorada e compreensível para todos os interessados no tema." [ANAMARIA DE MORAES, 2006]

Summary of the book

Ergodesign and information architecture approaches user centered design issues from different viewpoints: the clients, the designers, system analysts and information architects. The book is addressed to novice audiences (those interested in working in this field), and focusing on them it develops the content in a simple manner and with colloquial language. 'If, as the author Luiz Agner says, nowadays crisis regards in fact "how to transform information in knowledge", he started to fight the crisis when he decided to produce a goodhumoured and understandable book for all interested in this theme'. [ANAMARIA DE MORAES, 2006]

\section{Introdução}

O termo Arquitetura da Informação foi cunhado em 1997 por Richard Saul Wurman (1997) e passou a ganhar notoriedade em 1998 com Rosenfeld e Morville $(1998,2002)$ e seu "best-seller" Information Architecture for the World Wide Web. Embora os cientistas da informação já discutissem o assunto numa abordagem de conteúdo, a disciplina (hoje já vastamente divulgada e popularizada, fazendo parte inclusive de inúmeras grades curriculares de cursos de design e desenvolvimento de sistemas interativos) só foi de fato tomar fama a partir desta data. Até então muito se discutia a respeito da "desorientação do usuário", em abordagens ergonômicas e da 
psicologia cognitiva, sempre em relação a sistemas computadorizados. Vários autores dedicaram inúmeras pesquisas para tentar elucidar os problemas registrados pelos usuários durante 0 processo de interação humano-computador e apontar caminhos para resolvê-los. Pois esse é o tema do livro em questão.

O ponto inicial do livro é o que chama de "letargia cognitiva" - termo que usa para definir a atual situação de excesso de informação originando bloqueio mental e incapacidade individual de aquisição de conhecimento. Segundo o autor, a única saída para resolver tal problema é o desenvolvimento de um sistema hipertextual sob aspectos ergonômicos, centrado no usuário, visando a facilitação da Interação Humano-Computador (ergodesign).

Lidando com o tema de forma superficial, ainda que dentro do ponto de vista apenas da ergonomia, o autor aborda diversos aspectos associados à importância do design centrado no usuário, sempre numa linguagem simples, coloquial e por vezes até vulgar (usando gírias e vícios de linguagem), destinando claramente seu livro ao público jovem, estudante que pretende ingressar no universo do design web. Por abordar muito mais questões de design de interface e usabilidade, talvez o título do livro devesse não apenas circunscrever-se à arquitetura da informação, mas ao desenvolvimento de interfaces web ou experiência do usuário em websites.

\section{Sobre o tema}

Embora não mencionado no livro Ergodesign e arquitetura da informação, o autor discorre sobre o tema numa abordagem de design, ergonomia e engenharia de usabilidade, em detrimento de outras, um pouco mais afastadas da ergonomia, como a biblioteconomia ou comunicação social e jornalismo (ROSENFELD AND MORVILLE, 1998 e 2002). O foco no usuário é de fato uma premissa em todos os casos - sua compreensão a partir do seu nível de conhecimento e contextualização - mas o viés nos dois últimos casos é muito mais lingüístico e de comunicação.

Essa classificação se faz importante, pois qualquer outro olhar que se faça sobre o livro percebe-se que há um encurtamento do imenso universo que o tema abraça. Talvez por isso o autor esbarre sempre em argumentos que enfatizam a necessidade da presença do usuário nas pesquisas e invariavelmente acabe caindo em conceitos mais associados ao design de interfaces do que à arquitetura da informação propriamente dita.

A bem da verdade, é que o termo além de um pouco desgastado, gera conflitos e sobreposições com outras áreas, principalmente biblioteconomia e engenharia de usabilidade. Atualmente existem várias discussões a respeito do melhor termo a ser adotado. Recentemente, em uma lista de discussão, Tom Danehower, arquiteto da informação, defendeu o termo "User Experience Architect (UXA)" como um título mais apropriado para questões que de fato os Arquitetos da Informação lidam, como "definir estratégias de navegação e métricas eficientes, conduzir pesquisas, criar uma arquitetura de informação "disponibilizável", informar e tomar decisões sobre tecnologia, design e conteúdo, tudo no sentido de criar uma ilusão de experiência do usuário "perfeita". (DANEHOWER, 2007).

O próprio Agner questiona o termo e sugere um novo: AI2, acrescentando mais um "i" referente a interação. Percebe-se também a sua insatisfação com relação a cobertura do termo Arquitetura da Informação numa disciplina que lida muito mais com questões de navegação e interação do usuário do que organização da informação. Esse ponto, aliás, é o centro nervoso de discussões entre arquitetos da informação e biblioteconomistas e cientistas da informação: classificação e organização de conteúdo é atribuição dos dois últimos e existe desde a Biblioteca de Alexandria, aproximadamente em 330 a.c., a primeira biblioteca documentada da história humana. Por que só agora, com o advento da internet, se "criou" uma profissão nova para lidar com essas questões?

\section{A atual crise de como fazer para transformar informação em conhecimento}

Certamente a demanda hoje por um profissional organizador de conteúdo é muito maior do que antes da popularização da internet: pelo fato de lidarmos atualmente com um volume muito maior de informação do que há algum tempo atrás, além da velocidade que essas informações chegam até nós. Mas, é preciso ter em mente que a atribuição de organização da informação em si não nasceu com a internet. Citando aspectos políticos - tanto em questões governamentais quanto de empresas -, Luiz Agner faz uma rápida e interessante introdução levantando questões e apontando algumas reflexões para o nosso dia-a-dia, principalmente para designers e desenvolvedores de sistemas interativos de maneira geral. 
Em espaços virtuais administrar essa crise significa preocupar-se também com a interação. E é sobre esse aspecto que sua definição de navegação tem uma abordagem bastante

apropriada: "navegação é o movimento cognitivo através de espaços formados por informações e conhecimento". De fato existe uma navegação, mas não física, não palpável, mas imaginaria, num contexto fictício, na maioria das vezes criado pelo usuário quando e no lugar em que ele se encontra em determinado sistema interativo (website, intranet). É por vias invisíveis, nebulosas algumas vezes, que ele precisa entrar para chegar ao seu objetivo final. E é através de uma repetida interação entre o sistema e o usuário que sua meta é atingida, num ciclo constante, hora controlado e interpretado pela máquina, hora por ele, que se dá essa interação Humanocomputador (MAYHEW, 1992).

\section{Quanto à forma do livro}

Ao optar por um texto informal, abordando o tema de forma mais superficial, o autor por vezes enumera pontos que, ao serem apresentados de maneira muito resumida, sem uma explicação e contextualização prévia, aparecem perdidos, sem um porquê de estar ali. É o que acontece, por exemplo, com o capítulo Interfaces: nove regras que valem ouro. Expostos dessa forma soam quase que como uma cartilha que deva ser decorada por desenvolvedores web, quando na verdade surgiram de intensas pesquisas dos autores - incluindo o próprio Agner.

A regra número 8 - na cabeça: sete mais ou menos dois -, por exemplo, é uma questão extremamente polêmica, de um estudo que data de 1963 (MILLER, G., 1963) muito interessante pela sua descoberta na época, mas que precisa ser bem explicado para ser entendido. Regras de maneira geral são para ser seguidas. E nem todas as regras citadas se aplicam a todos os sistemas existentes. Talvez o melhor termo seria "recomendações". Infelizmente para se entender o processo humano de navegação e interação em um determinado sistema interativo não basta conhecer poucas regras e aplicá-las. É necessária muita pesquisa e algumas boas horas de dedicação e estudo. Sempre, como enfatiza o autor, buscando entender como o usuário faria, mas dentro de questões como:

- limitação cognitiva (PADOVANI, 1998; MAYHEW, 1992);

- 3 planos de conhecimento: com a máquina, com o conteúdo e com o sistema em questão

(NIELSEN, 1993)

- contexto em que se encontra.

\section{Conhecer os usuários}

Uma questão que ficou pouco clara no livro - provavelmente por essa opção de uma versão mais enxuta de conteúdo - foi a tão repetida frase "é necessário conhecer o usuário". Conhecer quem usa ou usará um sistema pesquisado é muito mais do que fazer uma classificação simplista do tipo experiente $\mathrm{x}$ iniciante. Conhecer os usuários significa:

1. Tê-lo definido no posicionamento estratégico do produto.

Não é verdade que todo e qualquer site deva servir para toda e qualquer pessoa com todo o tipo de alfabetização, cultura ou idade ou ainda dentro dos 3 planos de Nielsen (1993). Um produto (no caso, um sistema interativo) que não tenha passado antes por um bom trabalho de marketing e que o seu processo de desenvolvimento ou reformulação não leve em conta seus grupos de usuários - público-alvo - fracassará.

\section{Cla ssificá-los}

Uma vez definido o(s) grupo(s) de interesse, deve-se, aí sim, pesquisar suas necessidades, objetivos, conhecimentos, particularidades, métodos, estratégias de busca, hábitos de uso nesse universo, roteiro pré-estabelecido (modelo mental) etc. A classificação simplista existe para categorizar os sujeitos de forma a não haver desvios. E mesmo essa classificação pode ir além dos opostos "iniciantes x experientes".

\section{Arquitetura da Informação no Brasil}




\section{Infodesıg}

Como dito no início desta resenha, as informações trazidas pelo autor vêm muito mais da sua experiência acadêmica dentro da ótica da ergonomia (ou ergodesign, como ele prefere dizer) e da sua experiência profissional dentro de um órgão do governo - trazendo vivências importantes nesse momento que o e-Gov começa a tomar corpo no Brasil. Aspectos relacionados à disciplina Arquitetura da Informação ou "arquitetura da informação e interação" numa abordagem sistêmica acabaram por serem sobrepujadas por questões levantadas desde sua dissertação de mestrado: usabilidade e influências políticas na "cadeia produtiva" do design de interfaces.

De qualquer forma a iniciativa é inovadora e brilhante, incentivando estudantes a entrarem no universo do tema arquitetura da informação, como diz Peter Morville na apresentação do livro. Fica, no entanto, ainda a lacuna existente em relação a divulgação de pesquisas e práticas feitas por vários profissionais brasileiros que hoje já se dedicam ao assunto em equipes multidisciplinares, dentro de universos amplos e diferentes como sites de banco, de instituições públicas ou privadas onde a organização, classificação e busca do conteúdo sob o aspecto da experiência do usuário se tornaram tão eficientes, realizando excelentes trabalhos com resultados impactantes em relação a versões anteriores.

\section{Referências bibliográficas}

AGNER, Luiz. Ergodesign e arquitetura da informação: trabalhando com o usuário. Rio de Janeiro: Quartet, 2006. 173p.

DANEHOWER, T. [Sigia-I] IA or UXA? Which do you prefer?. 2007. Disponível em: http://www.info-arch.org/lists/sigia-l/0710/0022.html. Último acesso em 10/12/2007.

MAYHEW, D. Principles and Guidelines in software user interfaces design. Englewood Cliffs (New Jersey), PTR Prentice Hall. 1992. 619p.

MILLER, G. The magical number seven, plus or minus two: some limits on our capacity for processing information. Psychological Review 63, no. 2. 1956: 81-97

NIELSEN, J. Usability Engeneering. San Francisco (California), Morgan Kaufmann, 1993. 362p.

PADOVANI, S. Avaliação Ergonômica de Sistemas de Navegação em Hipertextos fechados. In: MORAES, Anamaria de. Dedign e Avaliação de Interface. Rio de Janeiro, iUsEr, 2002. 27-58.

ROSENFELD, L.; MORVILLE, P. Information Architecture for the World Wide Web. Beijing. O'Reilly. 2002. 2a Ed. 461p.

WURMAN, R. Information Architects. Zurich, Switzerland. Watson-Guptill Publishing. 1997.

\section{Sobre a autora}

Renata Zilse, Possui graduação em Desenho Industrial pela Faculdade da Cidade (1991), especialização em Design Gráfico pelo Senai - Centro de Artes Gráficas (1992) e mestrado em Design pela Pontifícia Universidade Católica do Rio de Janeiro (2004). Atualmente é sócia-diretora da dmp.br design (RJ), professor externo da Pontifícia Universidade Católica do Rio de Janeiro e professor assistente do Centro Universitário da Cidade. Tem experiência na área de Desenho Industrial, com ênfase em Webdesign, atuando principalmente nos seguintes temas: arquitetura da informação, ihc, navegação e design de interface. 